\title{
PRESENTACIÓN: APORTES DE LA ANTROPOLOGÍA Y GEOGRAFIA A LOS ESTUDIOS DEL TURISMO Y PUEBLOS INDÍGENAS
}

\section{FRANCISCA DE LA MAZA*, ISIS M. CUNHA LUSTOSA**, STEPHEN G. BAINES ${ }^{\star \star \star ~}$}

Las disciplinas antropológica y geográfica tienen mucho que aportar al estudio del turismo como un fenómeno social, pues "las prácticas turísticas contribuyen a la turistificación de los espacios creando lugares singulares [...] para y por el turismo. El turismo no solo está hecho de ritos como se presupone, pero, es todavía, un imaginario del espacio" (de Almeida, 2009, p. 1) ${ }^{1}$. Desde sus diversas perspectivas, las dos disciplinas con el aporte de la etnografía y de la etnogeografía ${ }^{2}$ (CLAVAL, 1997) pueden dar cuenta de un proceso complejo y político que afecta de múltiples y contemporáneas formas a las poblaciones locales. El análisis de los territorios "turistificados" (Almeida 1997, Cunha Lustosa, 2012, De la Maza, 2018) implica comprender este proceso en términos amplios considerando la mirada histórica y actual que incluye diversos agentes, tales como los habitantes originarios y locales, los académicos, consultoras y ONGs, los tours operadores, los empresarios turísticos, los funcionarios públicos y los propios turistas. La observación de estas interacciones en el contexto turístico, en la cual se manifiestan los agentes con sus historias, diversidades, motivaciones, imaginarios y estereotipos, es un campo propicio en el que la etnografía e etnogeografía pueden aportar a desentrañar las dinámicas contemporáneas que superan lo turístico. Más bien, el estudio del turismo desde estas perspectivas aporta a dar luces sobre temas tales como la construcción y expresión de las relaciones sociales, las desigualdades como el caso del "indigenismo empresarial" (Baines, 1995), el rol de las políticas públicas territoriales e indigenistas, de los liderazgos y de la academia, de empresarios y el gobierno, de los imaginarios de lugares turísticos y de las luchas y reivindicaciones políticas de pueblos indígenas por sus territorios, sus actividades de autogestión como el turismo y las reivindicaciones de sus derechos nacionales y internacionales.

El turismo debe entenderse como un fenómeno social que se expande en diversos territorios transformando la vida cotidiana de sus habitantes y los imaginarios de lugar. Esta transformación se ve promovida por diversos motivos, por ejemplo: por las características propias de los territorios, naturales y culturales, por políticas públicas que incentivan un desarrollo económico basado o complementado por el turismo e iniciativas propias de agentes del territorio y otros agentes que buscan fomentar formas de negocios turísticos.

\footnotetext{
* Dra. en Antropología. Académica Pontificia Universidad Católica de Chile, Villarrica, Chile. Fondecyt Regular 1170236 Correo-e: fcadelamaza@uc.cl

** Dra. en Geografía. Investigadora externa y profesora colaboradora Laboratorio de Estudios e Investigaciones de las Dinámicas Territoriales (Laboter)- Instituto de Estudios Socioambientales (IESA) / Universidad Federal de Goiás, Goiás, Brasil. Correo-e: isismclustosa@gmail.com

*** Dr. en Antropología. Profesor Titular Departamento de Antropología Universidad de Brasília, Coordinador del Laboratorio y Grupo de Estudios en Relaciones Interétnicas, Investigador PQ1ACNPq, Brasilia, Brasil. Correo-e: stephengbaines@gmail.com
} 
Los territorios indígenas no han estado ajenos a los procesos de turistificación, "lo que es el proceso de apropiación del espacio por el turismo" (según Dewailly \& Flamente, 1993, citado por Almeida, 1997, p. 3). En diversas partes del mundo, los territorios que son habitados históricamente por poblaciones preexistentes a los Estados Nacionales se han convertido en atractivos turísticos, ya sea por sus paisajes, atractivos naturales, culturales y patrimoniales. Esto es posible constatarlo en los artículos de este Dossier, tanto en Argentina como en Chile. De una u otra forma los cinco artículos apuntan a temas en común pero que se expresan diferenciadamente en lo local y nacional como fue observado en otras experiencias de pueblos indígenas del Brasil, Argentina y Chile presentadas en el V Coloquio Internacional de Turismo, Pueblos Indígenas, Comunidades tradicionales y Afrodescendientes (V CTurTI): Derechos Indígenas, Territorio y Desarrollo en Contextos Turísticos, realizado en Chile a partir del evento CTurTI originado y desarrollado en Brasil desde 2013 en el Laboter/IESA/UFG. Por lo tanto, este Dossier se complementa con el documento del V CTurTI que da cuenta de la sistematización de talleres que se realizaron en el marco de este coloquio internacional, el cual permite afirmar que las problemáticas que viven los pueblos indígenas, afrodescendientes y comunidades tradicionales son similares en América Latina.

El turismo de autogestión puede ser considerado un aliciente de fortalecimiento cultural, un "vector de la identidad étnica" (Cunha Lustosa, 2012), un medio de "reelaboración étnica-cultural" (Cunha Lustosa y Baines, 2015), una actividad para la visibilidad de los pueblos indígenas (Cunha Lustosa, 2012; Valverde, 2015) y también como una forma de comple- mentación económica. Pero esto muchas veces se ve entorpecido porque el control del turismo lo ejercen personas ajenas al territorio. El turismo puede profundizar las relaciones asimétricas de extrema desigualdad y dominación y explotación históricas entre pueblos indígenas, Estado y sociedad nacional. Esto se expresa en aspectos como la marginación de los procesos económicos turísticos, el uso de etiquetas culturales indígenas sin su participación, el uso de imágenes indígenas en actividades o productos turísticos sin su autorización, precariedad laboral, invasión turística a espacios culturales y espirituales, sobrepresión a los recursos naturales como el agua, tierra, minerales, recursos madereros, entre otros.

Sin embargo, los pueblos indígenas han desarrollado diversas estrategias para generar sus propias iniciativas y mecanismos de control y lucha territorial, tal como se expresa en los artículos de Impemba y Maragliano y en el de Molina. Organizaciones y familias indígenas participan directamente en el turismo ya sea como empresarios ${ }^{3}$ o como tour operadores (tal como se observa en experiencias en Chile), por medio de generación de redes y rutas que fortalecen virtuosamente la capacidad de agencia del turismo por los propios indígenas. Por otro lado, algunos sectores indígenas han profundizado su lucha por el control del territorio en contextos turísticos, ya que muchas veces el turismo que se desarrolla evidencia las desigualdades históricas y la pérdida territorial, al mostrar contradicciones entre un tipo de turismo de intereses especiales con la presencia de turismo masivo - de empresas extractivistas cercanas o presentes en el destino turístico.

Otro elemento relevante es el rol de las políticas públicas para fomentar el turismo en 
los territorios indígenas. Las políticas turísticas no necesariamente van de la mano con las políticas indigenistas $u$ otras políticas del territorio, tal como lo muestra Lacko en el caso de Argentina, la que llama política turística indigenista, y Choque relativo al norte de Chile, con el caso del Carnaval de Arica y las relaciones transnacionales. Por un lado, se ve como una oportunidad económica prioritaria o complementaria con otras vocaciones, por lo cual es una oportunidad para fortalecer los territorios, ya que puede, por ejemplo, generar empleo, atraer a inversionistas y generar nuevas empresas. Por otro lado, y relacionado a lo anterior, el turismo puede aportar a distinguir un territorio del otro a partir de ciertos elementos particulares y ojalá únicos de ese territorio, que lo hacen atractivo para visitar, pero también fortalece la identidad propia del lugar. Esto se muestra claramente en el proceso vitivinícola que desarrolla Herrera, considerándolo como una etnomercancía.

\section{Notas}

\footnotetext{
${ }^{1}$ Las citaciones son traducción propia, las originales se encuentran en francés y portugués.

${ }^{2}$ El objetivo de una investigación etnogeográfica puede ser tratar de entender mejor en qué consisten las relaciones que un grupo étnico mantiene con su territorio. Según los representantes de los diversos pueblos autóctonos, de hecho, eses vínculos constituyen lo
}

\section{Bibliografía}

Almeida, M.G de. (1997). Turistificação - os novos atores e imagens do litoral cearense. En: Encontro regonal de estudos geográficos, VI. João Pessoa. Anais do VI Encontro Regional de Estudos Geográficos: Nordeste, turismo, meio ambiente e globalização. João Pessoa, Recife: AGB, Neoplanos: 27-36.

(2008). A geografia imaginária dos lugares turísticos. IESA- Universidade Federal de Goiás. Recuperado de: http:// www.geomorfologia.ufv.br/simposio/simposio/trabalhos/ comunicacaocoordenada/008.pdf
Finalmente, otro aspecto es que el turismo también genera disputas al interior de los territorios. Esto se puede visualizar entre los propios habitantes del lugar, por ejemplo, en los pueblos indígenas sobre lo que se puede o no vender, sobre la legitimidad de vender la cultura, los peligros de la folclorización y las disputas por la autenticidad. Asimismo, sobre quién puede vender y cómo se controla el turismo en dichos territorios.

Por lo tanto, las perspectivas antropológicas y geográficas del turismo a partir de las lecturas del Dossier reflejan diversos puntos de vista de las investigaciones contemporáneas sobre turismo relacionado con los pueblos indígenas, afrodescendientes, territorios, acciones de reivindicaciones, políticas turísticas, políticas indígenas, prácticas productivas, prácticas indígenas reelaboradas, invisibilización, frontera, tradiciones agrarias, redes, rutas turísticas y otras categorías trabajadas en sus textos. único o uno de los elementos esenciales de su vida, de su identidad como persona y como grupo y, finalmente, de la coesión de toda su cultura (Birraux-Ziegler (1995, p. 173).

${ }^{3}$ En el caso de Chile este termino es distinto del Brasil, donde empresarios de turismo se refiere a los agentes no indígenas del turismo empresarial.

Baines, S. (1995). Os Waimiri-Atroari e a invenção social da etnicidade pelo indigenismo empresarial. Anuário Antropológico 19(1), 127-159.

Birraux-Ziegler, P. (1995). La territorialité des indiens Yanomami du nord du Brésil: aspects etnogeographiques et geopolitiques. En: Claval, Paul; Singaravelou. (Eds.). Ethnogéographies. Paris: L'Harmattan, 173-191.

Claval, P. (1999). Etnogeografias - Conclusão. Espaço e cultura. Rio de Janeiro: UERJ, (7), 69-74. 
Cunha, I. (2012). 281f. Os povos indígenas, o turismo e o território: um olhar sobre os Tremembé e os Jenipapo-Kanindé do Ceará. [Tese de Doutorado] - Universidade Federal de Goiás, Instituto de Estudos Socioambientais. Goiânia.

Cunha, I. \& Baines, S. (2015). Reelaboracão étnica-cultural dos "Tremembé da Barra do Mundaú" frente ao turismo: ressignificações indentitárias e festas In: Festas, Religiosidades e Saberes do Cerrado.1 ed.Anápolis: Editora UEG, 375-405.

De la Maza, F. (2018). Tourism in indigenous territories: impact of public policies and the tourism value of indigenous culture. Journal Latin American and Caribbean Ethnic Studies. 13(1), 94-111.

Valverde, S. (2015). "Veríamos a forma de aproveitar suas culturas e de fazer um produto turístico mais: relações interétnicas, cenificações e territorialidades divergentes no Norte da Patagônia Argentina”. En: Pereiro, Xerardo. (ed.), Almeida, Maria Geralda, Lustosa, Isis Maria Cunha (coeds.). Turismo em terras indígenas. Volume especial da Agália. Revista de Estudos na Cultura, 59-91. 